\title{
Comparative Analysis of Music Inheritance between Dai Nationality of Xishuangbanna and Northern Thailand
}

\author{
Haiyan Wang \\ Kunming University, Kunming, Yunnan, China
}

Keywords: Dai nationality of Xishuangbanna; Northern Thailand music; comparison; suggestion

\begin{abstract}
In the process of economic development, the music inheritance is crucial. The comparative analysis of music inheritance between Dai nationality of Xishuangbanna and Northern Thailand is the key aspect, which has become the focus of public attention. Through the comparative analysis, it can be seen that there has culture differences between Dai nationality of Xishuangbanna and Northern Thailand. The integration shall be strengthened through the comparative analysis between the two, and the value of music inheritance is highlighted. This paper deeply researches the music inheritance between Dai nationality of Xishuangbanna and Northern Thailand, and focuses on some specific suggestions to provide some help to relevant industry people.
\end{abstract}

\section{Introduction}

Dai nationality of Xishuangbanna and Northern Thailand is closely connected and inseparable with each other in music, language and faith. Especially the music, which has great significance to analyze the cultural difference between them. The inheritance and reservation of traditional music culture in both places is mainly due to the influence of religious belief and lifestyle. Through the analysis, we should learn from it, inherit the tradition, promote the new, respect the differences, and give play to the cultural charm of the two places. This will highlight the cultural heritage and promote the realization of great cultural development and prosperity.

\section{Relationship Analysis between Dai nationality of Xishuanbanna and Thai nationality of Thailand}

\subsection{Dai nationality and Thai nationality consanguinity.}

Among the ethnic minorities in China, the Dai nationality is one of the most important ethnic groups, mainly in Yunnan Province and other regions. Among them, the two most populated areas are the Xishuangbanna Dai Autonomous Prefecture and the Dehong Dai Nationality and Jingpo Nationality Autonomous Prefecture.

For the Dai language, it is the Sino Tibetan languages family and Zhung-dai branch. In the dialect aspect, it can be divided into the Xishuangbanna Dai, Dehong Dai, and so on. These two also exist writing.

Ethnic origins include the Shan ethnic group in Myanmar, Thailand's Thai ethnic group and Vietnam. According to the relevant data of the ancient Chinese Han nationality, it can be seen that in the branch of Baiyue, the ancestors of the Dai nationality play a certain role. There are dozens of titles, among which the highest frequency is "Baiyi", but Dai is a symbol of the "pursuit of freedom".

In the evolution of the long history, there are also some differences between the Dai and the Thai. For example, key area in northern Thailand is Chiangmai, which is one of the most important branches of Thailand. There is a certain difference between the details of customs and the central part of Bangkok. This phenomenon is mainly due to the frequent exchanges among the north of Thailand, the west of Myanmar and the east of Cambodia with the cultural diversity. There is a difference with the middle area[1]. Moreover, there is a unique ancient style in eastern Thailand, so 
it is worth comparing and analyzing with the Dai nationality of China.

\subsection{The cultural customs of the Dai and Thai nationality.}

During the continuous evolution and advancement of history, the culture between the Dai nationality of Yunnan and the northern part of Thailand has its own characteristics. However, there are many similarities on the surface, with a common "cultural circle". Its common ground is mainly reflected in:

\subsection{Language.}

For Diale dialect, it is a dialect spoken by the Dai nationality of Xishuangbanna and Thai nationality of northern Thailand. Both of them believe in Mahayana Buddhism. Therefore, the New Year is a common religious festival, which is worth celebrating. The celebration area of the representative works is the Chiangmai in the north of Thailand, which is the same as the celebration of western carnival. Moreover, the Close-door festival and Open-door festival are also important festivals.

\subsection{Buddhist temple.}

Buddhist temple is also extremely important in the lives of both people. Every Dai village and Thai village have Buddhist temples. The Buddhist temple in Dai village is also called the Burma temple. Because as early as a thousand years ago, Myanmar was gradually introduced to the Buddhism, and in the aspect of architecture and decoration, there was a close relationship with the Buddhist temple in northern Thailand.

\subsection{Dancing.}

Long-drum dance and Fawn Leb is the similar dance, which is the exclusive of northern Thailand.

Buddhism is a religion of the Dai people. Due to the influence of early animism, there is a certain spirituality for natural objects [2]. At the same time, Buddhism is also a religion of the Thai people. Early animism and Hindu influence still persisted. Therefore, before opening the bank, people need to put a spirit house at the door. The Hindu priest is invited to do it. However, the Buddhist is the real identity of the host.

\section{Cultural Analysis of Dai nationality in Xishuangbanna}

Xishuangbanna is located in southern Yunnan, close to Myanmar. The mainly work of the Dai people is cultivated, and the life style still has some flavor of tribal society. Religion is very popular in Yunnan, which deeply influences the local culture. Generally speaking, there are more similar places between the Dai and Thai nationality such as religion and life custom. The following will focus on the analysis of the Dai nationality characteristics, so as to give full play to the music culture of the Dai nationality.

\subsection{Music category. Folk song.}

First of all, mountain songs are widely sung in various ethnic groups. Dai folk songs are an important part of the music culture of the Dai nationality. Most of the mountain songs are sung in the fields of the mountains, and some songs celebrate the work of people in hard work [3], and they also celebrate the love between men and women. It can express and transmit the thoughts and feelings of oneself. The mountain songs has large influence on Buddhism. It can be seen from the folk songs that people are singing, which conveys people's yearning for and pursuit of a better life.

Secondly, for narrative songs, it is mainly about narration. Buddhist stories and primitive religious stories are important content. This type of song is characterized by narrative. The melody of narrative song is gentle and smooth, and there is a certain colloquial phenomenon. The content of love poems and stories is also influenced by Buddhism.

Finally, Dai song is also one of the key pieces of Xishuangbanna, which deeply influenced by 
other music culture such as Thailand and religion. Most of these songs are in religious festivals, so it is very necessary to carry out in-depth analysis and exploration. In the theme of singing, people yearn for a better life. The rhythm and regularity of songs have simple content, and very popular in the repertoire of Xishuangbanna.

\subsection{Singing and dancing music.}

In the folk dance, Yilahui is very popular among the Dai songs music. Butterfly Dance and Peacock Dance belongs to the pictographic dance. The flow of peacock dance is attracting attention, it integrates the morphological characteristics of local animals [4]. Moreover, its formation mainly benefits from the rich historical and cultural resources of the Dai nationality.

In addition, the court dance was formed in the development of the traditional royal dance of the Dai nationality. The influence can be rooted in the dance culture of different countries in Southeast Asia, which has become one of the unique dance forms.

\subsection{Music inheritance analysis of the current situation.}

Among the minority nationalities in Xishuangbanna, the status of the Dai nationality cannot be ignored. In terms of lifestyle, the Han nationality has little influence on it, and the traditional culture is not changing very fast. Many Musical Instruments and music of the Dai nationality have closely relationship related with life. According to the relevant survey data, the Erhu of Xiqin is one of the important examples to change the tradition [5]. Bitter songs and new house songs have already passed the popular climax. Therefore, the Dai social culture has certain similarities with other societies in both inheriting and innovating.

\section{Music Culture of Thai Nationality in Thailand}

The inheritance of traditional culture is diverse, and festivals are the direct embodiment of the way of inheritance. In Thai culture, festivals are an important manifestation of the relationship between the old and the young. Moreover, it also has a great effect on family, social values and codes of conduct, which can express the feelings and emotions of Thai people. The national characteristics of many festivals are extremely strong [6], and the relationship between various customs and traditional music is more closely related. The following is an in-depth analysis of several major festivals.

\subsection{Songkran Festival.}

In Thailand, New Year's Day, the Chinese New Year and the Songkran Festival are the new years that people need. As an important national holiday, Songkran Festival plays a crucial role in Thailand. Songkran Festival also known as "Water Splashing Festival". During the festival, people laugh, pray for each other, and smell of delicious food everywhere. The festive atmosphere is very strong.

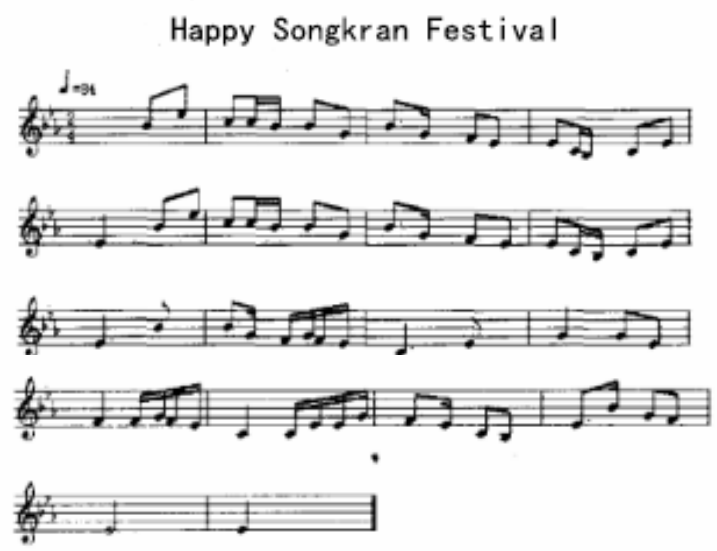

Figure 1 
In the Songkran Festival, music and songs were repeated and played, mainly playing a chorus of drums and gongs. Drums and drums were heard everywhere [7]. The melody is light and smooth.

The singing skill is not high, and it is popular with the public. Figure 1 is the example.

\subsection{Loy Kra Thong.}

In the traditional Thai festival, Loy Kra Thong occupies a certain position with very deep national characteristics. For Loy Kra Thong, the legends of its origin are more numerous, which conveys the awe of the gods and gives infinite longing and longing for the beautiful life in the future. During the festival, a number of large celebrations can be seen everywhere, the scene is extraordinary.

The water lamps in the street have various shapes and colors, and the night of the festival is very beautiful. People use banana leaves, fold them into various light boats, plant flowers, put them in water, and convey good wishes. The moral of the water lamp is to express people's reverence for the river god and the Buddha, to drive away the disease and summon the good.

At the same time, on this day, "water lantern" songs can be heard everywhere, the melody is beautiful and light, the rhythm of the song is also very suitable for dancing.

\section{Some Suggestions of Music Inheritance between Dai Nationality of Xishuangbanna and Northern Thailand}

\subsection{Make perfect market culture mechanism.}

The national government should give a certain support to the construction of cultural platform, which is fully reflected in the Dai nationality culture of the regional characteristics for religious culture [8]. The national government should pay attention to play its leading role and accelerate the construction of a folk culture display platform. At the same time, we should also build a perfect market culture institution and strictly regulate the local music cultural heritage channels.

\subsection{Create a distinctive brand of religious culture.}

Under the strong impetus of market economy, the publicity effect of brand effect is ideal, and it is necessary to actively create and reshape the Dai nationality culture and the Thailand culture. Transform the Dai religion into one of the propaganda symbols, constantly improve the utilization efficiency of various media network resources, and ensure the steady promotion of propaganda efficiency. In addition, it is necessary to deeply analyze and develop its added value, make good use of various resources and create a good consumption space.

\section{Summary}

From the above, strengthen the music inheritance analysis between Xishuangbanna and Northern Thailand is necessary. It will combine the two cultures and realize the cultural integration. The deep analysis and comparison of the music relationship between Xishuangbanna and Northern Thailand can highlight the regional cultural characteristics and religious culture. Then it will promote the culture of Dai nationnality and Thailand sustainable development and standardization.

\section{References}

[1] Wang Yuanxin, Language Living of “One Village Two Countries” -- Investigation on Language Usage and Attitude of Villagers in Yunjing Village, Ruili city of Yunnan province[J] Journal of Shaanxi Normal University(Philosophy and Social Sciences Edition) ,2017,46(04):147-160.

[2] Li Weilin, A cross-border Comparison of Traditional Music Instruments Played by Shan-Dai Nationalities Living in China, Laos, Burma, and Thailand as Evidenced in Plucked and String Instruments [J] Chinese Music, ,2017(02):74-83+137.

[3] Li Quan. Early Common Historical Memory and National Identity of Thai nationality in China 
and Thailand [J]. Journal of Hubei University for Nationalities (Philosophy and Social Sciences), 2017, 35(01):37-41.

[4] Yang Minkang. Singing Art of the Buddhist Festival in Southern China -- taking the Buddhist Temple in Chiangmai, Kaopansah as an example [J]. National Arts, 2014(03):53-60.

[5] Huang Xinyu. Cultural Identification of Zhuang and Dai Ethnic Groups between Southwest China and Southeast Asia and Its Inspiration [J] Journal of Qinzhou University, 2013, 28(10):96-100.

[6] Yang Lizhou, Yue Shufang. Water Custom Comparison between Thai People of Thailand and Dai Nationality in Xishuangbanna of Yunnan Province [J]. Journal of Yunnan Minzu University (Social Sciences), 2013, 30(04):153-157.

[7] Yang Minkang. Comparative Study on the Musical Instruments of the Buddhist Culture Circle in Yunnan and Southeast Asia-- Take the Dissemination and Distribution of the Sun Drum and Drum Music as an Example [J]. Journal of the Central Conservatory of Music, 2013(02):52-61+83.

[8] Yang Minkang. A Comparative Study of the Vocal Music in the Theravada Buddhist Ceremonies of the Shan-Dai Ethnic Groups in Yunnan and Southeast Asia [J]. Journal of the Central Conservatory of Music, 2002(02):20-29+89. 